\title{
Histomorphological spectrum of endometrial lesion in women presenting with abnormal uterine bleeding: A 3-year study at a tertiary care center
}

\author{
Sharma R. ${ }^{1}$, Mishra P. ${ }^{2}$, Kumar N. ${ }^{3}$, Srivastava . $^{4}$ \\ ${ }^{1}$ Dr. Ritu Sharma, Assistant Professor, ${ }^{2}$ Dr. Poornima Mishra, Assistant Professor, ${ }^{3}$ Dr. (Brig.) Nikhilesh Kumar, \\ Professor (Brig.) and Head; all above authors are attached with Department of Pathology, ${ }^{4}$ Dr. Prachi Srivastava, \\ Assistant Professor, Department of Obs \& Gynae, all authors are affiliated with T.S. Misra Medical College and Hospital \\ Lucknow, Uttar Pradesh, India.
}

Corresponding Author: Dr. Poornima Mishra, Assistant Professor, TSM Medical College \& Hospital, Amausi, Lucknow (U.P.). E-mail: histopath6@gmail.com

\begin{abstract}
Introduction: Abnormal uterine bleeding (AUB) is the most common presentation amongst the women of all age groups attending the gynecology Out Patient Department. Histopathological evaluation of the endometrial samples plays a significant role in the diagnosis of abnormal uterine bleeding. Aim: To determine the various histomorphological patterns of the endometrium in women presenting with AUB. Material and Method: A retrospective analysis of 183 patients age ranged from 15 to 71 years, presenting with AUB was done who underwent endometrial sampling during a 3-year period from August 2015 to July 2018 in Department of Pathology at T.S Misra Medical College and hospital. Detailed clinical history like age, menstrual status including painful bleeding, heavy menstrual bleeding, periodicity \& regularity of cycle were obtained from the case records. Patients were categorized into reproductive age group, perimenopausal and postmenopausal. Specimens were routinely processed and stained with Haematoxylin\& Eosin stain and microscopic morphological evaluation was done. Results: The most common age group affected is perimnopausal presenting withAUB frequently seen in $41-50$ years of age group (47.5\%). The commonest Histomorphological pattern in these patients was proliferative endometrium (38.8\%), secretory endometrium $(16.3 \%)$, endometrial hyperplasia seen in 22 cases (12.0\%), hormonal changes/Pill endometrium were seen in $6.0 \%$ of the cases and least number cases were of endometrial carcinoma forming $1.1 \%$ of the total cases taken in the study. Conclusion: In our study patients with AUB show variable pathology on endometrial biopsy as milder as inflammatory cause to as notorious as malignancy.
\end{abstract}

Key words: Endometrium, Postmenopausal, Malignancy, Abnormal uterine bleeding

\section{Introduction}

Abnormal uterine bleeding (AUB) is the most common presentation amongst the women of all age groups attending the Gynecology Out Patient Department. AUBis the term used to describe any departure from normal menstruation or from a normal menstrual cycle pattern. The key characteristics are regularity, frequency, heaviness of flow and duration of flow [1]. Menstrual bleeding is considered abnormal when the pattern is irregular of prolonged duration (i.e $>20$ days) in individual cycle lengths over a period of 1 year or heavy menstrual bleeding. Recently, the International Federation of Gynecology and Obstetrics working group on menstrual disorder has developed a

Manuscript received: $04^{\text {th }}$ November 2018

Reviewed: $14^{\text {th }}$ November 2018

Author Corrected: $20^{\text {th }}$ November 2018

Accepted for Publication: $27^{\text {th }}$ November 2018 classification system (PALM-COEIN) for causes of the AUB in non-gravid women of reproductive age. There are nine main categories, which are arranged according to the acronym PALM-COEIN: Polyp; adenomyosis; leiomyoma; malignancy and hyperplasia; coagulopathy; ovulatory dysfunction; endometritis; iatrogenic; and not yet classified [2]. Two types of causes including functional causes like normal cyclical endometrium, abnormal physiological changes of endometrium (atrophic endometrium, weakly proliferative and disordered proliferative endometrium) and organic lesions like chronic endometritis, endometrial hyperplasia, endometrial polyp, carcinomas and pregnancy related complications [2]. In reproductive age group heavy menstrual bleeding accounts for $30 \%$ of total DUB cases [3], while postmenopausal bleeding. 


\section{Original Research Article}

accounts for $5 \%$ of all gynaecological visits. Histopathological examination of endometrial sample is used for the diagnosis of majority of lesions. Endometrial biopsy and curettage are chief sampling methods [4].

\section{Materials and Methods}

A retrospective study was undertaken which included 183 endometrial samples with a clinical diagnosis of AUB.

The study was carried out in the Department of Pathology, T.S. Misra Medical College \& Hospital Lucknow (U.P.), India, over a period of 3 years from August 2015 to July 2018.

Inclusion Criteria: Patients with isolated endometrial causes of abnormal uterine bleeding were included for study. Endometrial samples (Biopsy or Dilation \& Curettage) obtained from those patients were studied.
Exclusion Criteria: Patients presenting with AUB due to cervical or vaginal pathology and haemostatic disorders were excluded from the study.

Detailed clinical history like age, menstrual status including painful bleeding, heavy menstrual bleeding, periodicity \& regularity of cycle were obtained from the case records. Relevant findings of general and systemic examination were recorded. Endometrial samples were obtained from dilatation and curettage or endometrial biopsy. Specimens were received in $10 \%$ formalin. Gross morphology of these tissue samples was studied. These were studied grossly and were processed in automated tissue processor. Five-micron thick paraffin embedded serial sections were taken and stained by Haematoxylin and Eosin stain. Special stains like ZeilNeelson stain and Periodic Acid Schiff stain were done as per the case requirement. Detailed microscopic examination was done in each case. The data was recorded and tabulated under relevant headings and thorough analysis was done.

\section{Results}

During the study period of 3 years, a total of 183 endometrial samples were selected.

Table-1 (a): Distribution according to various age groups

\begin{tabular}{|c|c|}
\hline Age group (Years) & Number of patients (\%) \\
\hline $15-20$ & $06(3.3 \%)$ \\
\hline $21-30$ & $25(13.7 \%)$ \\
\hline $31-40$ & $46(25.1 \%)$ \\
\hline $41-50$ & $87(47.5 \%)$ \\
\hline $51-60$ & $11(6.1 \%)$ \\
\hline $61-70$ & $05(2.7 \%)$ \\
\hline$>70$ & $03(1.6 \%)$ \\
\hline
\end{tabular}

Table-1(b): Cases in different age groups

\begin{tabular}{|c|c|}
\hline Age Group & Cases \\
\hline Reproductive & $77(42.1 \%)$ \\
\hline Perimenopausal & $87(47.5 \%)$ \\
\hline Postmenopausal & $19(10.4 \%)$ \\
\hline Total & $\mathbf{1 8 3}$ \\
\hline
\end{tabular}

Minimum age of presentation of AUB was 15 years and maximum was 71 years. Most common age group affected was between $4^{\text {th }}$ and $5^{\text {th }}$ decade which is perimenopausal age group $(47.5 \%)$, (Table1a $\left.\& 1 \mathrm{~b}\right)$.

Table No-2: Relationship of AUB with bleeding pattern

\begin{tabular}{|l|c|}
\hline Bleeding Pattern & No. of Patients(\%) \\
\hline Disturbances of Regularity & $30(16.4 \%)$ \\
\hline Disturbances of frequency & $28(15.3 \%)$ \\
\hline Disturbances of heaviness of flow & $76(41.5 \%)$ \\
\hline Disturbances of the duration of flow & $15(8.2 \%)$ \\
\hline Abnormal bleeding with hormonaltherapy & $13(7.1 \%)$ \\
\hline Irregular Non-menstrual bleeding & $10(5.5 \%)$ \\
\hline Bleeding outside reproductive age & $11(6.0 \%)$ \\
\hline
\end{tabular}




\section{Original Research Article}

Table 2 shows that disturbances of heaviness of flow was the commonest bleeding pattern seen in 76 patients (41.5\%) followed by disturbances of regularity of menstrual cycle seen in 30 patients $(16.4 \%)$. Least common bleeding pattern was irregular non- menstrual bleeding seen in 10 patients $(5.5 \%)$.

Table-3: According to Endometrial Histopathology report.

\begin{tabular}{|c|l|c|c|}
\hline S. No. & Histomorphology finding & Cases & Percentage \% \\
\hline 1. & Proliferative Endometrium & 71 & $38.8 \%$ \\
\hline 2. & Secretory Endometrium & 30 & $16.4 \%$ \\
\hline 3. & Endometrial Hyperplasia & 22 & $12.0 \%$ \\
\hline 4. & Disordered Proliferative Endometrium & 12 & $6.5 \%$ \\
\hline 5. & Hormonal change/pill endometrium & 11 & $6.0 \%$ \\
\hline 6. & Inadequate & 11 & $6.0 \%$ \\
\hline 7. & Atrophic Endometrium & 08 & $4.4 \%$ \\
\hline 8. & Pregnancy related changes & 06 & $3.3 \%$ \\
\hline 9. & Endometritis & 06 & $3.3 \%$ \\
\hline 10. & Endometrial Polyp & 04 & $2.2 \%$ \\
\hline 11. & Endometrial Carcinoma & 02 & $1.1 \%$ \\
\hline
\end{tabular}

After detailed microscopic examination, depending upon their histomorphological features all the cases were categorized into 11 groups (Table 3). Amongst these, maximum number of the samples showed proliferative phase 71(38.8\%), followed by 30 cases $(16.4 \%)$ of secretory phase and endometrial hyperplasia $22(12 \%)$.

Disordered proliferative endometrium was observed in $12(6.5 \%)$ cases. Hormonal changes/ pill endometrium was observed in 11 cases $(6.0 \%)$. Total 8 cases $(4.4 \%)$ revealed atrophic endometrium. Both pregnancy related changes and endometritis were reported in 6 cases $(3.3 \%)$ each.

Among pregnancy related changes there were 2 cases of retained product of conception (RPOC) and partial mole and single case of complete mole and Arias - Stella reaction each.

Endometritis was seen in 6(3.3\%) cases, out of which 1 case showed necrotizing granulomatous endometritis with cystic change i.e caseating granulomas, Langhans type of giant cells, areas of necrosis with cystic dilation of glands. 3 cases showed acute on chronic endometritis \& remaining 2 cases show chronic endometritis (Fig 1a \& 1b).

Endometrial polyps were seen in $4(2.2 \%)$ cases, out of which 2 cases showed hyperplastic endometrial polyp. Endometrial carcinoma which is common in postmenopausal women was encountered in $2(1.1 \%)$ cases.

Scant endometrial tissue with predominantly blood clot, autolyzed samples and tissue with suboptimal fixation that hindered the microscopic evaluation were considered inadequate. In our study 11 samples (6.2\%) were inadequate for evaluation and were excluded from the study group.

Table-4: Percentage of Endometrial hyperplasia cases

\begin{tabular}{|c|l|c|c|}
\hline S.No. & Histologic types & Number cases & Percentage (\%) \\
\hline 1 & Simple hyperplasia without atypia & 12 & $54.5 \%$ \\
\hline 2 & Complex hyperplasia without atypia & 05 & $22.7 \%$ \\
\hline 3 & Simple hyperplasia with atypia & 03 & $13.6 \%$ \\
\hline 4 & Complex hyperplasia with atypia & 02 & $9.2 \%$ \\
\hline
\end{tabular}

More than half of the histomorphologically reported cases of endometrial hyperplasia showed simple hyperplasia without atypia among which few showed cystic changes. 3 cases (13.6\%) showed simple hyperplasia with atypia and whereas 5 $(22.7 \%)$ cases showed complex hyperplasia without atypia and $2(9.1 \%)$ cases showed complex hyperplasia with atypia (Table 4). 


\section{Original Research Article}

Table-5: Distribution of cases according to different age group.

\begin{tabular}{|l|c|c|c|c|c|c|c|}
\hline Age Groups & $\mathbf{1 5 - 2 0}$ & $\mathbf{2 1 - 3 0}$ & $\mathbf{3 1 - 4 0}$ & $\mathbf{4 1 - 5 0}$ & $\mathbf{5 1 - 6 0}$ & $\mathbf{6 1 - 7 0}$ & $>\mathbf{7 0}$ \\
\hline Proliferative endometrium & 02 & 09 & 14 & 45 & 01 & - & - \\
\hline SecretoryEndometrium & 01 & 07 & 11 & 11 & - & - & - \\
\hline EndometriumHyperplasia & - & 01 & 06 & 13 & 02 & - & - \\
\hline $\begin{array}{l}\text { Disordered } \\
\text { ProliferativeEndometrium }\end{array}$ & - & 01 & 05 & 04 & 02 & - & - \\
\hline Hormonal/Pill endometrium & - & 01 & 03 & 05 & 01 & 01 & - \\
\hline Atrophic & - & - & - & 02 & 02 & 01 & 03 \\
\hline Inadequate & - & 01 & 03 & 05 & 01 & 01 & - \\
\hline PregnancyChange & 02 & 03 & 01 & - & - & - & - \\
\hline Endometritis & - & 02 & 01 & 02 & - & 01 & - \\
\hline Endometrial polyp & 01 & - & 02 & - & 01 & - & - \\
\hline Endo Ca & - & - & - & - & 01 & 01 & - \\
\hline Total & $\mathbf{0 6}$ & $\mathbf{2 5}$ & $\mathbf{4 6}$ & $\mathbf{8 7}$ & $\mathbf{1 1}$ & $\mathbf{0 5}$ & $\mathbf{0 3}$ \\
\hline
\end{tabular}

Maximum number of proliferative endometrium, endometrial hyperplasia and pill endometrium were present in the $5^{\text {th }}$ decade. Maximum number of cases of disordered proliferative endometrium in $4^{\text {th }}$ and $5^{\text {th }}$ decades. Endometrial carcinoma was observed in $6^{\text {th }} \& 7^{\text {th }}$ decade of life (Table 5), (Fig 2\&4).
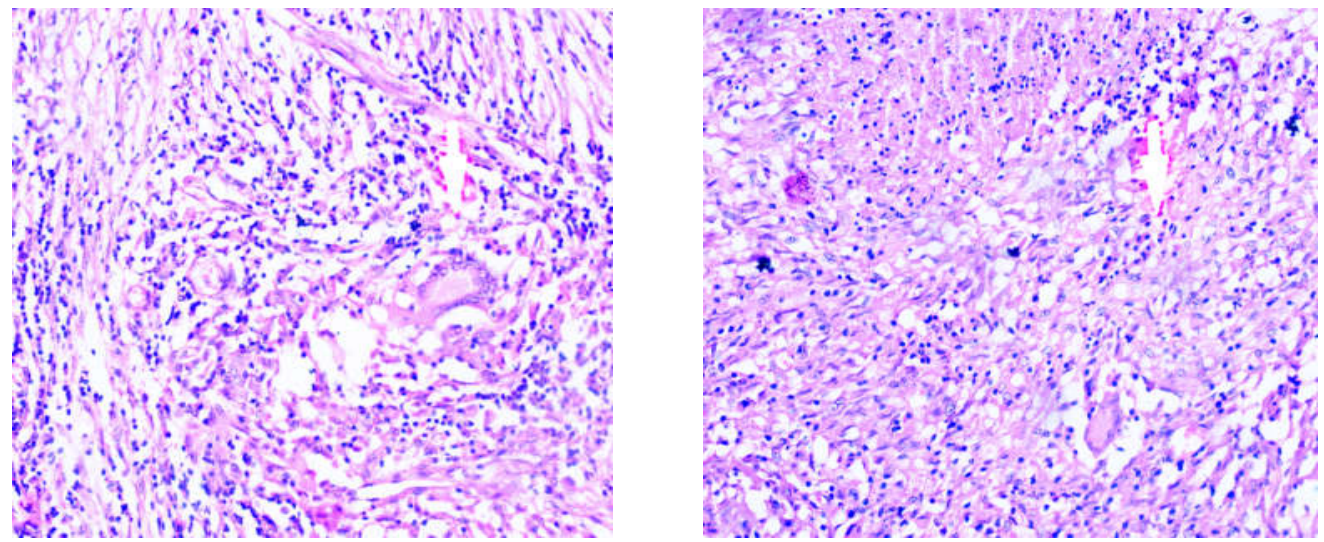

Fig-1a \& 1b: Photomicrograph ofNecrotizing Granulomatous Endometritis showing Caseating granulomas, langhans type of giant cells \& areas of necrosis $(40 x \& 4 x)$.
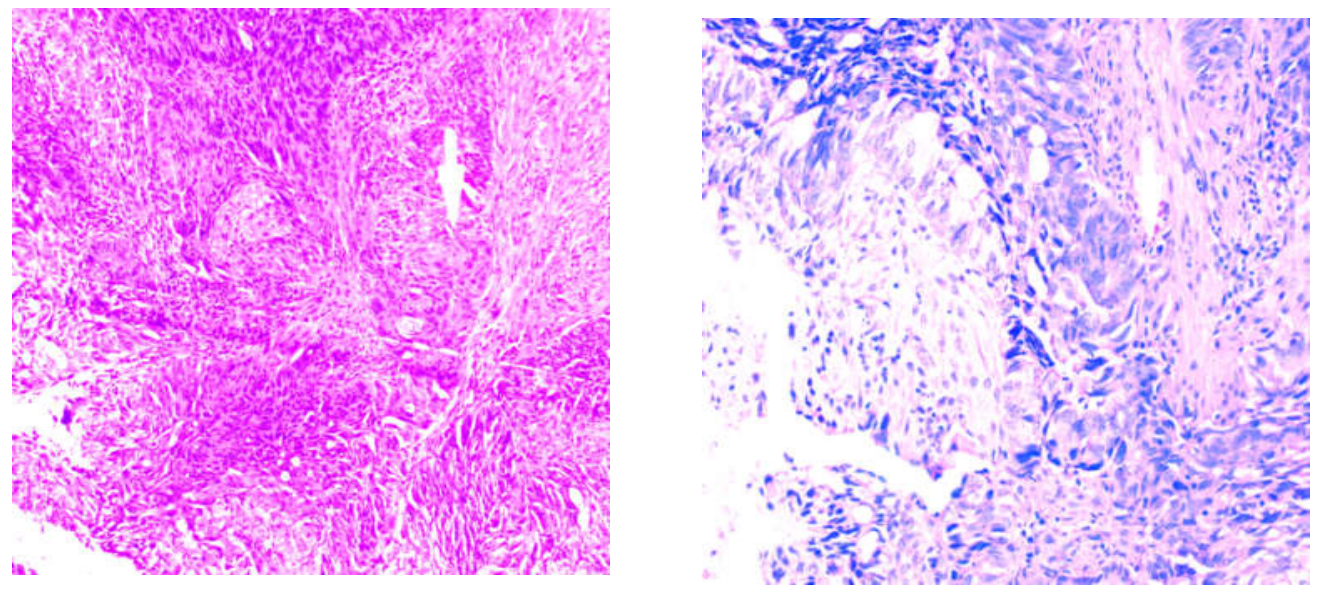

Fig 2a \& 2b: Photomicrograph of Endometrial Carcinoma showing invasive complex endometrial gland with anaplastic epithelial cells and pleomorphic hyperchromatic nuclei (10x and 40x) 


\section{Original Research Article}
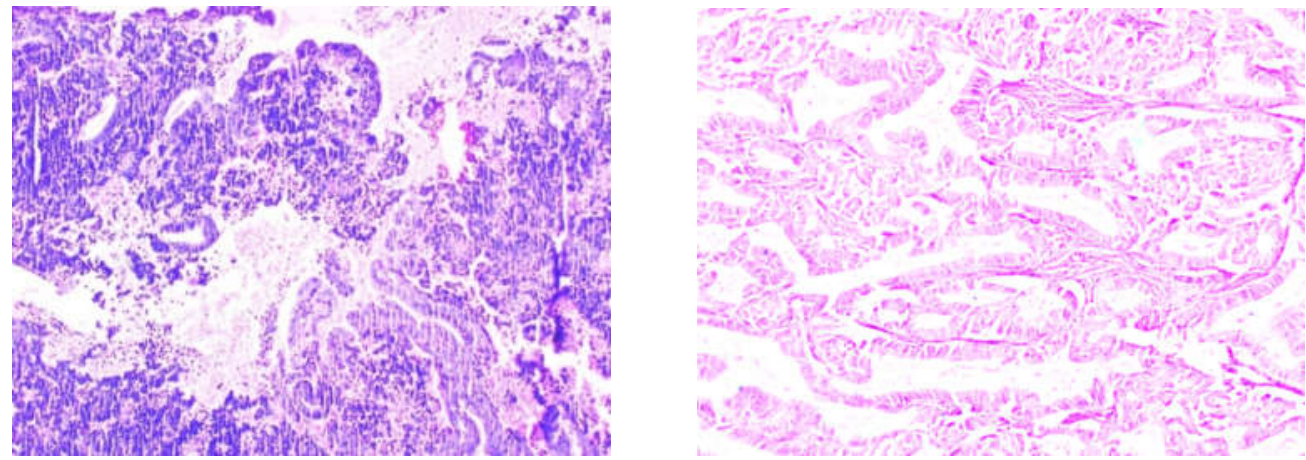

Fig-3: Complex Hyperplasia with atypia (4x), Fig 4: Endometrial Ca with anaplasticback-to-back glands. (40 x) Table-6: Comparison of various histopathological patterns of endometrium in AUB by various authors

\begin{tabular}{|c|c|c|c|c|c|c|}
\hline $\begin{array}{c}\text { Endometrial } \\
\text { Pattern }\end{array}$ & $\begin{array}{l}\text { Present } \\
\text { Study }\end{array}$ & $\begin{array}{c}\text { Ayesha } \\
\text { Fatima } \\
{[10](2017)}\end{array}$ & $\begin{array}{l}\text { Sarika [5] } \\
\text { Et al } \\
(2016)\end{array}$ & $\begin{array}{c}\text { AnuradhaSal } \\
\text { vi [13] et al } \\
(2015)\end{array}$ & $\begin{array}{c}\text { Rajesh } \\
\text { Patil [8] } \\
\text { (2013) }\end{array}$ & $\begin{array}{c}\text { BhoomikaDa } \\
\text { dhiana [14] } \\
(2013)\end{array}$ \\
\hline Proliferative & $71(38.8 \%)$ & $56(19.7 \%)$ & $84(41.6 \%)$ & $93(37.2 \%)$ & $42(22.1 \%)$ & $32(21.3 \%)$ \\
\hline Secretory & $30(16.3 \%)$ & $29(10.2 \%)$ & $35(17.3 \%)$ & $46(18.4 \%)$ & $37(19.5 \%)$ & $23(15.3 \%)$ \\
\hline Hyperplasia & $22(12.0 \%)$ & $132(46.5 \%)$ & $31(15.3 \%)$ & $63(25.2 \%)$ & $76(40 \%)$ & $40(26.7 \%)$ \\
\hline $\begin{array}{c}\text { Disorder } \\
\text { Proliferative }\end{array}$ & $12(6.5 \%)$ & $14(4.93 \%)$ & $15(7.4 \%)$ & - & - & $\begin{array}{c}\text { Irregular } \\
\text { proliferative } \\
4(2.7 \%)\end{array}$ \\
\hline $\begin{array}{c}\text { Pill/Hormonal } \\
\text { Change }\end{array}$ & $11(6.0 \%)$ & - & $13(6.4 \%)$ & - & - & - \\
\hline Endometritis & $06(3.3 \%)$ & - & $06(2.97 \%)$ & - & - & - \\
\hline Polyp & $04(2.2 \%)$ & - & $03(1.5 \%)$ & - & - & - \\
\hline Atrophic & $08(4.4 \%)$ & $07(2.5 \%)$ & $04(1.98 \%)$ & $20(8 \%)$ & - & - \\
\hline Endoca & $02(1.1 \%)$ & - & $04(1.98 \%)$ & - & - & - \\
\hline Pregnancy & $06(3.3 \%)$ & - & $01(0.51 \%)$ & - & $\begin{array}{l}\text { Others } \\
2(1.06 \%\end{array}$ & $\begin{array}{c}\text { Others } \\
38(25.3 \%)\end{array}$ \\
\hline Inadequate & $11(6.0 \%)$ & $16(5.62 \%)$ & $06(2.97 \%)$ & - & - & $06(4.0 \%)$ \\
\hline
\end{tabular}

\section{Discussion}

The endometrium is undergoing regular cyclical changes in response to the recurrenthormonal changes of the ovulatory cycles thus it is crucial to take endometrial sample at an appropriate time of ovulatory cycle. Inadequate clinical information also leads to erroneous diagnosis. AUB with organic cause can be due to reproductive disease, iatrogenic causes and systemic diseases. When no specific cause of AUB is found, then by exclusion, a diagnosis of dysfunctional uterine bleeding (DUB) is assumed.

AUB occurs as heavy, prolonged or acyclic flow at perimenopausal period or as spotting or minimal bleeding at post-menopausal period and requires proper evaluation to rule out malignancy. In the current study 183 specimens of endometrium (curettage/biopsy) were evaluated in order to find age, clinical and pathological features. The incidence of abnormal uterine bleeding was more in perimenopausal age group than postmenopausal age group. This might be due to earlier evaluation. In our study majority of patients belonged to 41-50 years age group. This is in concordance to the studies done by Sarika et al [5], Doraiswami S et al [6] and Muzaffar et al [7]. whereas the study conducted by Rajesh Patil et al [8] and Mitra K et al [9] showed AUB predominantly in a decade earlier i.e. age group 31-40 year and was recorded to be $45.2 \%$ and $62 \%$ respectively.

The most common bleeding pattern encountered in present study was heavy menstrual bleeding 57.3\% which is comparable with the study by Ayesha Fatima [10] and Rajesh Patil et al [8]. Comparison of various histopathological patterns of endometrium in AUB by 


\section{Original Research Article}

various authors is shown in Table 6. Normal physiological phases of endometrium, such as proliferative and secretory pattern were encountered in maximum number of cases. Proliferative endometrium comprised of 71 cases (38.8\%) in our study, this finding is in very much alliance with the studies done by Sarika et al [5], Rajshri P et al [11] and Khare et al [12]. This is followed by secretory endometrium in $30(16.3 \%)$ cases.

The third commonest lesion was hyperplasia observed in $22(12 \%)$ cases with its maximum number of patients falling in the age group of 41 to 50 years which is comparable with study done by Sarika et al [5] (15.3\%) and is in discordance with the studies done by Rajesh Patil et al [8] (40\%), Anuradha salviet al [13] (25.2\%), Bhoomika Dadhania et al [14] (26.7\%), who observed a high incidence of endometrial hyperplasia. Endometrial hyperplasia is commonly seen in perimenopausal age group due to failure of ovulation. Persistent unripe follicles expose the endometrium to excessive and prolonged estrogenic action. The incidence of simple hyperplasia was more common in the perimenopausal age group. In our study there were only two cases (9\%) of complex hyperplasia with atypia, this is in contrast to the findings of Rajshri P et al [11], Khare et al [12] who observed a higher incidence of $19.35 \%$ \& 33.3\% respectively.

$12(6.5 \%)$ cases showed disordered proliferative pattern in our study, which is in accordance with Jetley $\mathrm{S}$ et al [15]. The term 'disordered proliferative endometrium' is a complex term that denotes an endometrium that is hyperplastic but without an increase in endometrial volume. Although it resembles a simple hyperplasia, but the process is focal rather than diffuse. Hormonal change on endometrium was seen in $11(6.0 \%)$ cases in our study which was in concordance with the study done by Sarkiaet al [5] who reported 13 cases (6.43\%). But Khare et al [12] showed effects of hormones in 9 cases only, whereas Abidet al [16] showed a higher incidence of $27 \%$.

Patients with chronic endometritis can present with AUB, pelvic pain and infertility, which are distressful symptoms and thus needs to be timely and accurately diagnosed because with specific treatment endometrium starts functioning normally. Study done by Jetly et al [15] found 20 cases of endometritis which is quite a higher incidence comparing to our study in which this condition was diagnosed in few patients (6 cases), out of which 3 cases shows acute on chronic endometritis, 2 cases showed chronic endometritis and remaining 1 case showed necrotizing granulomatous endometritis with cystic change. Atrophic endometrium was seen between 41-60 years age group i.e. premenopausal and postmenopausal age groups. The incidence of atrophic endometrium in the present study (4.4\%) is lower as compared with results shown by Abdullah LS et al [17] and Sarika et al [5]. It is now well known that atrophic endometrium leads to bleeding and it is postulated to be due to anatomical changes in the vasculature or abnormalities in the local haemostatic mechanisms. The expanding cystic glands lead to distension and thinning of veins overlying these glands and eventually making the vessel prone to injury.

Endometrial polyps are defined as polypoidal fragments lined with epithelium on its three sides, fibrous stroma and thick walled blood vessels. The incidence of endometrial polyp was $(2.2 \%)$ in our study, which is in accordance with Jetley $\mathrm{S}$ et al [15] (2.7\%) and Doraiswami $S$ et al [6] in $(11.2 \%) .2$ cases $(1.1 \%)$ of endometrial carcinoma were found in this study which is common in post-menopausal age group. This finding is comparable to the findings in Sarikaet al [5] (1.98\%).

On the contrary, this finding is lower than the incidence recorded by Doraiswami et al [6] (4.4\%), Khare et al [12] (3.7\%) \& Bhatta et al [18] (5.7\%). Endogenous and exogenous hyperestrogenism is the most common risk factors for endometrial carcinoma. The most common precursor lesion for endometrial carcinoma is endometrial hyperplasia. Changes of pregnancy were seen in 6(3.3\%) cases in 15-40 year age with findings of RPOC, partial mole, complete mole and Arias-stella reaction. Eleven cases $(6.0 \%)$ of endometrial biopsies were scanty and inadequate for opinion.

\section{Conclusion}

The histopathological study of endometrium in females with abnormal uterine bleeding in all the age groups plays an important role in diagnosing various histopathological patterns and aetiopathological factors.

Present study confronted a wide spectrum of histomorphological changes in endometrial biopsies of patients presenting with AUB ranging from normal endometrium to malignancy.

However histopathological evaluation of endometrial biopsies is a challenging task for pathologist due to the frequent inadequate endometrial sampling requiring proper screening of endometrial samples for prompt but accurate diagnosis.

Findings: Nil; Conflict of Interest: Non initiated. Permission from IRB: Ye 


\section{Original Research Article}

\section{References}

1. Ian S. Fraser MD et al. The FIGO Recommendation on Terminologies and Definitions for Normal and Abnormal Uterine Bleeding. Seminars in Reproductive medicine/Vol 29/ Number 5/2011.

2. Munro MG, Critchley HO, Broder MS, et al. FIGO classification system (PALM-COEIN) for causes of abnormal uterine bleeding in nongravid women of reproductive age. Int J Gynaecol Obstet. 2011 Apr; 113 (1):3-13. doi: 10.1016/j.ijgo. 2010.11. 011. Epub 2011 Feb 22.

3. Moodley M, Roberts C. Clinical pathway for the evaluation of postmenopausal bleeding with an emphasis on endometrial cancer detection. J Obstet Gynaecol. 2004 Oct;24 (7):736-41.

4. Dueholm M. Levonorgestrel-IUD should be offered before hysterectomy for abnormal uterine bleeding without uterine structural abnormalities: there are no more excuses! Acta Obstet GynecolScand 2009;88 (12): 1302-1304.

5. Sarika More, et al. Histomorphological Spectrum of lesions in Endometrial Biopsy in Patients Presenting with Abnormal Uterine Bleeding- A study of 202 Cases.JCont Med A Dent May-Aug 2016 Vol 4 Issue 2.

6. Doraiswami S, et al. Study of endometrial pathology in abnormal uterine bleeding. The Journal of Obstretics\& Gynecology of India. 2011;61(4):426-430.

7. Muzaffar M, Akhtar KA, Yasmin S, et al. Menstrual irregularities with excessive blood loss: a clinico-pathological correlation. J Pak Med Assoc. 2005 Nov;55(11):486-9.

8. Patil R, Patil RK, Andola SK, Laheru V, Bhandar M. Histopathological spectrum of endometrium in dysfunctional uterine bleeding. Int $\mathrm{J}$ Biol Med Res 2013; 4(1):2798-801.

9. Mitra K, Chowdhury MK. Histological and histochemical study of endometrium in dysfunctional uterine haemorrhage. J Indian Med Assoc. 2003 Aug;101(8):484-5.
10. Ayesha Fatima, V.D. Dombale. Morphological Spectrum of Endometrium in Dysfunctional Uterine Bleeding. Indian Journal of Pathology: Research and Practice/Vol 6 Number 2/April- June 2017.

11. Rajshri P. Damale et al. Clinicopathological Spectrum of Endometrial Changes in Perimenopausal and Post-menopausal Abnormal Uterine Bleeding: A 2 Years Study. Journal of Clinical and Diagnostic Research. 2013 Dec, Vol-7(12): 2774-2776.

12. Khare A, et al. Morphological spectrum of endometrium in patients presenting with uterine bleeding. Peoples's Journal of scientific research. 2012; 5(2):13-16.

13. Anuradha Salvi et al.Spectrum of Endometrial Histopathology in Women Presenting with Abnormal Uterine Bleeding.Sch. J. App. Med. Sci.,2015; 3(1A) : $1-4$.

14. Dadhania B, Gauravi D, Agrawat A, Pujara K. Histopathological study of endometrium in dysfunctional uterine bleeding. Int $J$ Res Med 2013;2(1):20-4

15. Jetley $\mathrm{S}$ et al. Morphological spectrum of endometrial pathology in middle aged women with atypical uterine bleeding: A study of 219 cases. Journal of Mid-life Health Oct-Dec 2013 ; Vol 4 : Issue 4.

16. Abid M, Hashmi AA, Malik B, et al. Clinical pattern and spectrum of endometrial pathologies in patients with abnormal uterine bleeding in Pakistan: need to adopt a more conservative approach to treatment. BMC Womens Health. 2014 Nov 5;14:132. doi: 10.1186/s12905-014-0132-7.

17. Abdullah LS, Bondagji NS. Histopathological Pattern of Endometrial Sampling Performed for Abnormal Uterine Bleeding. Bahrain Medical Bulletin, 2011;33(4):1-6.

18. Bhatta S, Sinha AK; Histopathological study of endometrium in abnormal uterine bleeding. $\mathrm{J}$ of Pathology Nepal, 2012; 2(4): 297-300.

\section{How to cite this article?}

Sharma R., Mishra P., Kumar N., Srivastava P. Histomorphological spectrum of endometrial lesion in women presenting with abnormal uterine bleeding: A 3-year study at a tertiary care center. Trop J Path Micro 2018;4(7):525531.doi:10.17511/jopm.2018.107.08. 